\begin{tabular}{cc|c}
\hline Tar. Bil. Der. & Journal of Agricultural Sciences \\
& $\begin{array}{c}\text { Dergi web sayfası: } \\
\text { www.agri.ankara.edu.tr/dergi }\end{array}$ & Journal homepage: \\
& www.agri.ankara.edu.tr/journal
\end{tabular}

\title{
Estimates of Genetic Parameters for Body Weight in Turkish Holstein Bulls using Random Regression Model
}

\author{
Aşkın GALIÇ⿻̧一 ${ }^{\mathrm{a}}$, Çiğdem TAKMA ${ }^{\mathrm{b}}$ \\ ${ }^{a}$ Akdeniz University, Faculty of Agriculture, Department of Animal Science, 07070, Antalya, TURKEY \\ ${ }^{{ }^{b}}$ Ege University, Faculty of Agriculture, Department of Animal Science, Biometry and Genetics Unit, 35100, Bornova, Izmir, TURKEY
}

\section{ARTICLE INFO}

Research Article

DOI: 10.15832 /ankutbd.417422

Corresponding Author: Așkın GALİÇ, E-mail: galic@akdeniz.edu.tr, Tel: +90 (242) 3102497

Received: 20 April 2018, Received in Revised Form: 25 July 2018, Accepted: 10 August 2018

\begin{abstract}
The objective of this study was to estimate genetic parameters for the body weights of Turkish Holstein bulls using the random regression model. The data set consists of 1475 body weight records from 395 Holstein bulls raised in the same herd. Body weight records of bulls aged between 32 and 725 days old were collected at approximately two-month intervals from December 2013 to October 2014. In the study body weight measurements made on the same day were accepted as a group and the bulls were grouped into 10 different groups according to their age. The additive genetic and permanent environmental effects were estimated using DFREML algorithm by third order Legendre polynomials. The additive genetic variance estimates ranged from 10.73 to 4867.07 , the phenotypic variance estimates ranged from 382.84 to 5514.86 and permanent environmental variance estimates ranged from 0.33 to 63.27 . The heritability values were estimated between 0.03 to 0.90 . The phenotypic and additive genetic correlations between body weights were positively estimated between 0.085 to 0.89 and 0.53 to 0.94 , respectively. It was concluded that use of body weight at an earlier age will give advantage in breeding studies for body weight at slaughter.
\end{abstract}

Keywords: Holstein; Heritability; Meat; Random regression model

(C) Ankara Üniversitesi Ziraat Fakültesi

\section{Introduction}

Approximately $21 \%$ of world meat production is obtained from cattle while this rate exceeds $32 \%$ for red meat (Anonymous 2016). Even though the breeds and systems used for cattle meat production differs from each other, the basic logic is to use breeds with high growth capacity and/or rate and to grow animals at as low cost as possible. Even if the animals are from the same breed, due to diversity in climate and herd management, growth and efficiency may differ according to the regions (Ferraz \& Eler 2010).

There are various researches on the weights and growth rates of cattlefrom different ages and regions of the world. In these researches, the data from the meat-oriented breeds, like Nellore, Angus or Hereford, are used as material (Albuquerque \& Meyer 2001; Arango et al 2004; Bohmanova et al 2005; Menéndez-Buxadera et al 2008; Baldi et al 2012; Martinez et al 2012). In Turkey, there are not many animals from breeds listed above. Almost half 
of the cattle presence of Turkey consists of Holstein or its crosses. Cattle meat is generally obtained through fattening of male animals at dairy farms that have breeds like Holstein, Simmental and Brown Swiss that are considered to be efficient in both milk and meat purposes. Additionally, in terms of average carcass weight, Turkey is far behind the EU and USA. Recently, the average carcass weight has increased to $250 \mathrm{~kg}$ depending on imports. In some countries such as USA, UK, Germany, France, this amount reaches 300-350 kg (Anonymous 2016). In addition, cattle fattening in Turkey is mostly done in a closed farming style and the range lands-based farming is limited and therefore the costs are high. Furthermore, imports are frequently discussed to both meet the domestic market demand and reduce the meat prices. However, the projections of the Ministry of Food, Agriculture and Livestock have shown that in order to meet the increasing demand, Turkey's cattle meat production, which was 882 thousand tonnes in 2014, should be increased by almost $50 \%$ in 10 years and one of the solution ideas was the development of policies towards the breeding of multi-purpose breeds (Anonymous 2015).

On the other hand, genetic breeding studies for the improvement of efficiency of the animals used in Turkey for meat production are highly inadequate. Whereas around the world; weights and weight gains at specific ages or during specific periods are commonly applied as selection criteria in most beef cattle breeding programs, since these traits show moderate to high genetic correlations with carcass weight, are easy to measure, and respond to selection (Razook et al 2001; Baldi et al 2012). Parkkonen et al (2000) reported that, the heritability estimates for slaughter weight were estimated between 0.07 and 0.10 . Genetic correlations between slaughter weight and fleshiness were estimated to be 0.38 for males and 0.65 for females. In another study, heritabilities for body weights, carcass weights and carcass fleshiness were estimated 0.17 to 0.22 , while genetic correlations between them ranged from 0.54 to 0.78 (Liinamo \& Van Arendonk 1999).
Growth can be defined as a measurement sequence that changes gradually until reaching a plateau. The measurements at any points on this line have a correlation with each other because of collecting them from same individual. The similarities among measurements increase as interval of time goes closer, but decrease as interval of time increases. When the relationship between the measurements during the growth period of cattle are taken into consideration, genetic parameter and breeding value estimations will become much more reliable and as a result, the precision level will increase in selection. Random regression models are the test day models that consider the change in variance components throughout the growth period (Jaffrezic et al 2002; Schenkel et al 2002; Nephawe et al 2006; Menéndez-Buxadera et al 2008; Silva et al 2013).

As mentioned above, there is a gap in the genetic breeding studies of Turkey for the utilization of the live weight of the animals used for meat production and for the increase of efficiency. This research estimates the (co) variance components, genetic parameters for the live weight of male Holstein, using a random regression model. This way, the aim is to both draw attention to the subject and provide leadership for more extensive studies that will be conducted in this field.

\section{Material and Methods}

A total of 1475 live weight records taken between December 2013 and October 2014 from 395 male Holstein raised at the same farm, located in the south of Turkey (latitude $37^{\circ} 8^{\prime}$ north and longitude $30^{\circ} 39^{\prime}$ east), were used for the research. This region is characterized by a warm and temperate climate, with average annual temperature and rainfall of $19^{\circ} \mathrm{C}$ and $1009 \mathrm{~mm}$, respectively. The numbers of animals, records and subgroups included in the analysis are given in Table 1. Live weight records were taken in approximately two-month intervals from male cattle at the age of 32 to 725 days. The records used in the research were categorized in 10 different stages according to age groups and the descriptive statistics of the terms are given in Table 2. 
Table 1- Numerical information of the material

\begin{tabular}{lr}
\hline Number of bull used & 395 \\
with 2 records & 74 \\
with 3 records & 105 \\
with 4 records & 95 \\
with 5 records & 94 \\
with 6 records & 27 \\
\hline Number of sire & 61 \\
\hline Number of dam & 375 \\
\hline Number of group according to the weighing date & 17 \\
\hline Number of record & 1475 \\
\hline
\end{tabular}

Table 2- Descriptive statistics of live weight measurements taken at different stages

\begin{tabular}{ccrrrrr}
\hline Stage & $\begin{array}{c}\text { Age } \\
\text { (month) }\end{array}$ & $N$ & Mean & SE & Min & Max \\
\hline 1 & $1-2$ & 57 & 72.56 & 0.70 & 58 & 84 \\
2 & $3-4$ & 46 & 150.61 & 3.87 & 100 & 208 \\
3 & $5-6$ & 192 & 194.27 & 2.46 & 109 & 278 \\
4 & $7-8$ & 254 & 254.50 & 2.39 & 137 & 361 \\
5 & $9-10$ & 234 & 312.07 & 3.00 & 173 & 455 \\
6 & $11-12$ & 215 & 375.23 & 3.49 & 210 & 487 \\
7 & $13-14$ & 198 & 436.36 & 4.33 & 288 & 615 \\
8 & $15-16$ & 183 & 475.71 & 4.53 & 331 & 656 \\
9 & $17-18$ & 73 & 519.26 & 7.18 & 353 & 739 \\
10 & $19+$ & 23 & 550.30 & 20.70 & 372 & 832 \\
\hline & Total & 1475 & 332.69 & 3.33 & 58 & 832 \\
\hline
\end{tabular}

The live weight measurements conducted on the same day at the farm were considered a group in the research while the data shown below have been analyzed through the random regression model. (Co) variances of random regression coefficients and heritability values were estimated by REML using the DXMRR subroutine of the DFREML software package, version $3.0 \beta$ (Meyer 1998). Estimates were obtained by using AI-REML algorithm, thereby avoiding problems with "derivative-free" possible local max estimates. Third order Legendre polynomials were used to define the (co)variance structure between the observations of the same individual. The general model can be presented as follows: $y_{i j k}=T G_{i}+\sum_{m=0}^{\theta_{a}-1} a_{j m} z_{k m} \sum_{m=0}^{\theta_{p}-1} p_{j m} z_{k m}+e_{i j k}$

Where; the $y_{i j k}$ is the body weight $(\mathrm{kg}), T G_{i}$ is the effect of $i^{\text {th }}$ weighting group, a and $p$ is the random regression coefficients for additive genetic and permanent environmental effects, $\theta_{a}$ and $\theta_{p}$ are the orders of fit additive genetic and permanent environmental effects, $z_{k m}$ is the $\mathrm{m}^{\text {th }}$ legendre polynomial for $\mathrm{k}^{\text {th }}$ term and $e_{i j k}$ is the error term (assumed to be homogeneous for 10 stages).

\section{Results and Discussion}

The additive genetic, permanent environmental and phenotypic variances and the heritability estimations are given in Figure 1. It has been determined that additive genetic variance increases rapidly with advanced age and even though it was 10.73 in the first stage, it has reached 4867.07 in the $10^{\text {th }}$ stage. Phenotypic variance estimations have also shown the same tendency as the additive genetic variances; while it was 382.84 in the first stage, it was estimated to be 5514.86 in the last stage. Course of the additive genetic variances have shown similarities with the studies of Albuquerque \& Meyer (2001), Nobre et al (2003), Lopes et al (2012) and Silva et al (2013) on the Nellore cattle. In Silva et al (2013), phenotypic variances have shown a faster increase than additive genetic variances. In

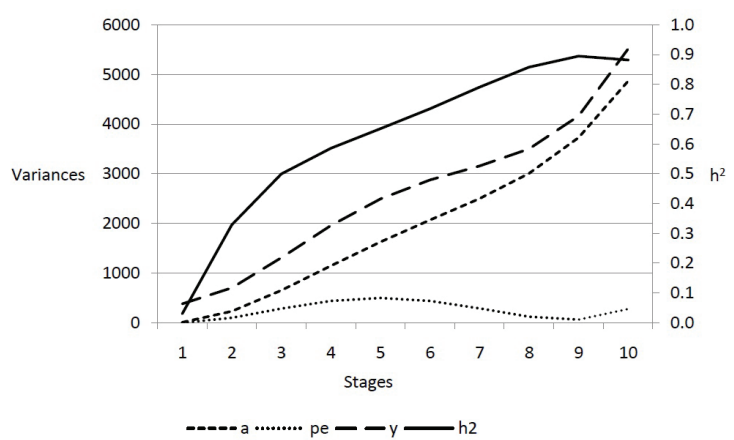

Figure 1- Estimates for additive genetic (a), permanent environmental (pe) and phenotypic (y) variance and heritability $\left(h^{2}\right)$ 
Arango et al (2004) research on the live weight of Angus and Hereford cattle, it has been determined that additive genetic variance slowly increases with advancing age. In the aforementioned research, there aren't any reports of an increase in phenotypic variances for the first two years.

On the other hand, in this research, the permanent environmental variances for the first stage and $9^{\text {th }}$ stage live weight were estimated to be respectively 0.33 and 63.27. Permanent environmental variance for the $5^{\text {th }}$ stage live weight was estimated to be the highest with 496.82. Even though permanent environmental variance estimations have a tendency to decrease with advancing age, it has been determined that permanent environmental variances have a much more constant structure than additive genetic and phenotypic variance (Figure 3 ). Silva et al (2013) has reported that there is some increase in permanent environmental variances especially after one year of age, but it has been identified that this increase is not as much as the increase in other variances. Valente et al (2008) and Lopes et al (2012) have reached the conclusion that the permanent environmental variance estimations increase with the age.

In our research, major differences have been identified between the heritability estimations obtained for the live weight from different age terms. Heritability was estimated to be 0.03 for the $1^{\text {st }}$ stage live weight that consists of the first two months after birth, while it ranged between 0.33 $\left(2^{\text {nd }}\right.$ stage $)$ and $0.90\left(9^{\text {th }}\right.$ stage $)$ for other stages. These changes in heritability are thought to be the result of the increase in additive genetic and phenotypic variance estimations for live weight with advancing age, the fact that the change in permanent environmental variance is almost none existent and that the model has the assumption of the existence of a constant error variance. Similar with this research, the previous research on the topic report that the heritability estimations increase with age (Albuquerque \& Meyer 2001; Nobre et al 2003; Silva et al 2013). In addition to these researches, there is also researchwhich report that heritability estimations have tendency to decrease or fluctuate with increased age (Arango et al 2004; Valente et al 2008; Baldi et al 2012; Lopes et al 2012).

The additive genetic covariance estimations between the stages have increased with increased age. Additive genetic variance-covariance matrix is presented in Figure 2 as three-dimensional graph. Estimations of additive genetic correlations can be seen in Figure 3. General status of the phenotypic variance-covariance estimations is similar with those of the additive genetics. As seen in Figure 4, there are no sharp transitions between the variances and covariance values on the diagonal. This case is the result of the fact that environmental factors from the term don't play an important role in the

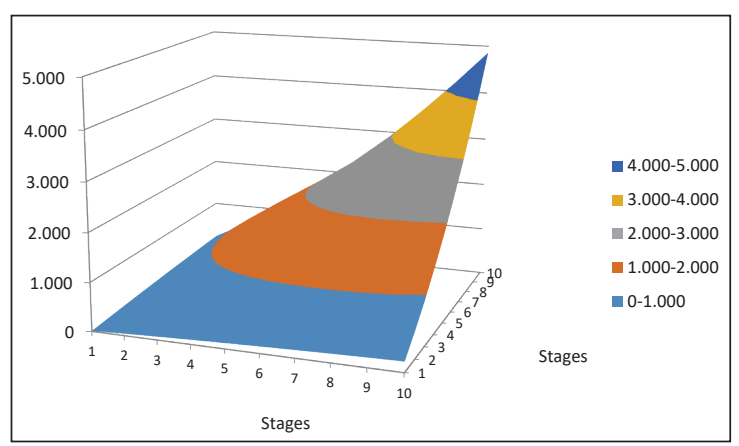

Figure 2- Additive genetic covariance estimations between stages

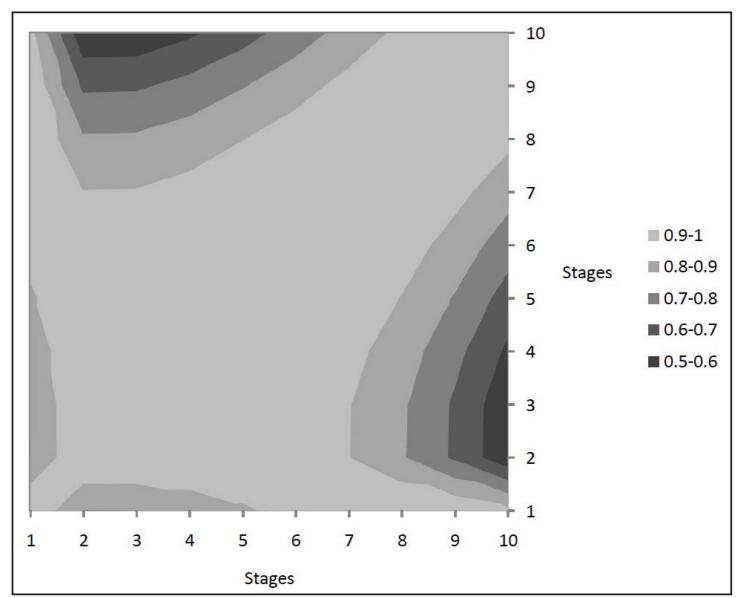

Figure 3- Additive genetic correlation estimations between stages 


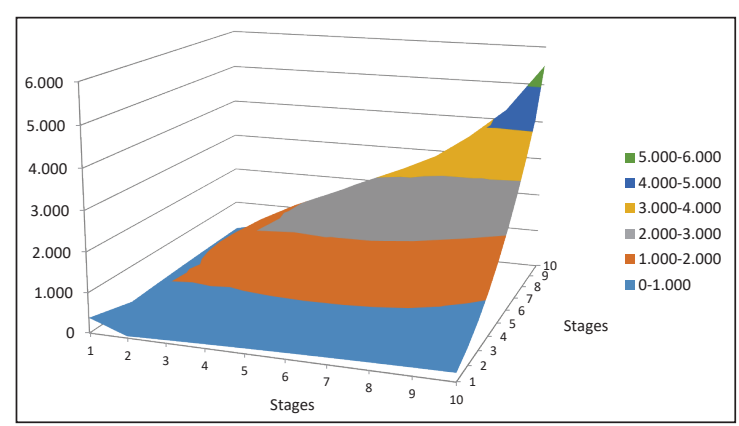

Figure 4- Phenotypic covariance estimations between stages

variation. In phenotypic correlation estimations, the lowest value has been obtained as $0.09{\text { (between } 1^{\text {st }}}^{\text {st }}$ and $2^{\text {nd }}$ stages) while the highest value was obtained as 0.890 (between $9^{\text {th }}$ and $10^{\text {th }}$ stages). Compared to this research, Martinez et al (2012) has reported higher phenotypic correlation estimates for the live weight at advanced ages.

At the end of the analysis, it can be seen that the additive genetic correlations between live weights are higher than phenotypic correlations (Figure 3 and Figure 5). The additive genetic correlations have shown a tendency to be high as expected when close to each other while they decreased with the

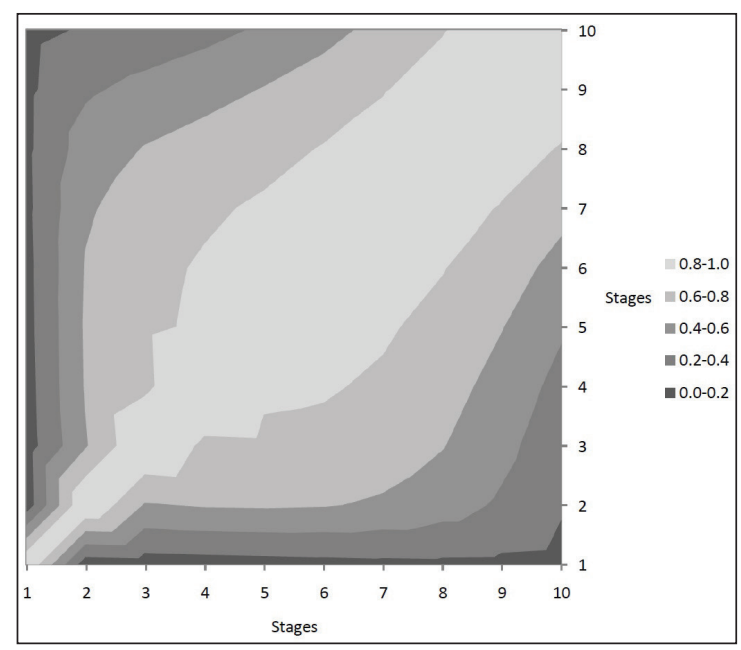

Figure 5- Phenotypic correlation estimations between stages increase in the distance between the stages. The lowest estimation for additive genetic correlations has been observed as 0.53 (between $2^{\text {nd }}$ and $10^{\text {th }}$ stages). While the $7^{\text {th }}$ stage has become the age group with the highest correlation amongst the other stages, with 0.94; the age group with the lowest has become the $10^{\text {th }}$ stage with 0.75 .

High and positive genetic correlation estimates indicate the fact that most of the genes that cause higher live weight in those ages are the same. High level of additive genetic correlations between different age groups can also be interpreted as the fact that early period weight can be used for studies of live weight at slaughter age (Boligon et al 2010). The values reported in the research based on the simulation of Bohmanova et al (2005) and the research conducted by Martinez et al (2012) using different breeds, have also similarly varied between 0.50-1.00. While the additive genetic correlations between the birth weight and live weight in advanced ages were low in Silva et al (2013) research, the values between other age groups have been observed to be high. Nobre et al (2003) and Valente et al (2008) have indicated that the correlations between 1 year of age and older are high.

\section{Conclusions}

This research has estimated parameters for live weight of stock materials raised in Turkey, using a random regression model. In conclusion, it has been observed that the change of variances of live weight at the age of 1-24 months can be adequately defined by using random regression model that contains Legendre polynomials, and as a result, it is possible to take advantages of the random regression models. However, low number of records per animal may cause low level of effectiveness for the random regression models. More research on the use of random regression models about growth is required in order to make sure that numerical problems and/ or wrong parameters do not reduce the effectiveness of breeding studies. It has been concluded that younger live weight can be used for the breeding studies of live weight at slaughter age. 


\section{References}

Albuquerque L G \& Meyer K (2001). Estimates of covariance functions for growth from birth to 630 days of age in Nellore cattle. Journal of Animal Science 79: 2776-2789

Anonymous (2015). Red Meat Strategy. Republic of Turkey Ministry of Food, Agriculture and Livestock, General Directorate of Livestock. Downloaded in December, 16, 2016 from http://www.tarim.gov.tr/HAYGEM/ Belgeler/ Hayvanc1k\%20Et\%20Stratejisi.pdf

Anonymous (2016). Food and Agricultural Organization of the United Nations. Retrieved in December, 16, 2016 from http://www.fao.org/faostat/en/\#data

Arango J A, Cundiff L V \& Van Vleck L D (2004). Covariance functions and random regression models for cow weight in beef cattle. Journal of Animal Science 82: 54-67

Baldi F, Albuquerque L G, Cyrillo J N S G, Branco R H, de Oliveira B C \& Mercadante M E Z (2012). Genetic parameter estimates for live weight and daily live weight gain obtained for Nellore bulls in a test station using different models. Livestock Science 144: 148156

Bohmanova J, Misztal I \& Bertrand J K (2005). Studies on multiple trait and random regression models for genetic evaluation of beef cattle for growth. Journal of Animal Science 83: 62-67

Boligon A A, Mercadante M E Z, Forni S, Lobo R B \& Albuquerque L G (2010). Covariance functions for body weight from birth to maturity in Nellore cows. Journal of Animal Science 88: 849-859

Ferraz J B S \& Eler J P (2010). Public x private partnership in the development of animal breeding research. Revista Brasileira de Zootecnia 39: 216-222

Jaffrezic F, White I M S, Thompson R \& Visscher P M (2002). Contrasting models for lactation curve analysis. Journal of Dairy Science 85: 968-975

Liinamo A E \& Van Arendonk J A M (1999). Combining selection for carcass quality, body weight, and milk traits in dairy cattle. Journal of Dairy Science 82: 802-809

Lopes F B, Magnabosco C U, Paulini F, Silva M C, Miyagi E S \& Lobo R B (2012). Analysis of longitudinal data of Nellore cattle from performance test at pasture using random regression model. Springerplus 1: 49-55

Martinez C A, Elzo M A, Manrique C \& Jimenez A (2012). Genetic parameters and breeding values for live weight using random regression models in a Bos taurus-Bos indicus multibreed cattle population in Colombia. Revista Colombiana de Ciencias Pecuarias 25: 548-565

Menéndez-Buxadera A, Carleos C, Baro J A, Villa A \& Cañón J (2008). Multi-trait and random regression approaches for addressing the wide range of weaning ages in Asturiana de los Valles beef cattle for genetic parameter estimation. Journal of Animal Science 86: 278-286

Meyer K (1998). DFREML $3.0 \beta$ Program Package and User Notes. Animal Genetics and Breeding Unit, Univ. New England, Armidale, New South Wales, Australia.

Nephawe K A, Maiawashe A \& Theron H E (2006). The effect of herd of origin by year on post-weaning traits of young beef bulls at centralized testing centres in South Africa. South African Journal of Animal Science 36: 33-39

Nobre P R C, Misztal I, Tsuruta S, Bertrand J K, Silva L O C \& Lopes P S (2003). Analyses of growth curves of Nellore cattle by multiple-trait and random regression models. Journal of Animal Science 81: 918-926

Parkkonen P, Liinamo A E \& Ojala M (2000). Estimates of genetic parameters for carcass traits in Finnish Ayrshire and Holstein-Friesian. Livestock Production Science 64: 203-213

Razook A G, Figueiredo LA, Nardon R F, Gonçalves J N S \& Ruggieri A C (2001). Breed and selection for postweaning weight effects on feedlot and carcass traits for the $15^{\text {th }}$ progeny of Sertãozinho (SP-Brazil) Zebu and Caracu herds. Revista Brasileira de Zootecnia 30: 115-124

Schenkel F S, Miller S P, Jamrozik J \& Wilton J W (2002). Two-step and random regression analyses of weight gain of station-tested beef bulls. Journal of Animal Science 80: 1497-1507

Silva T B R, Araújo C V, Bittencourt T C B S C, Araújo S I, Lôbo R B, Bezerra L A F \& Silva A A (2013). Use of orthogonal functions in random regression models in describing genetic variance in Nellore cattle. Revista Brasileira de Zootecnia 42: 254-258

Valente B D, Silva M A, Silva L O C, Bergman J A G, Pereira J C C, Fridrich A B, Ferreira I C \& Correa G S S (2008). Covariance structure of body weight in function of age for Nellore animals from Southeast and Center West of Brazil. Arquivo Brasileiro de Medicina. Veterinária e Zootecnia 60: 389-400 